\title{
58. DATA REPORT: ASSESSMENT OF THE PRECISION OF LEG 135 SHIPBOARD XRF ANALYSES AND THE CONTAMINATION INTRODUCED BY CRUSHING IN TUNGSTEN CARBIDE ${ }^{1}$
}

\author{
Janet M. Hergt ${ }^{2}$ and Donald R. Sims, $\mathrm{Jr}^{3}{ }^{3}$
}

\begin{abstract}
Statistical analysis of X-ray fluorescence data acquired during Leg 135 indicates that this instrument produces data of comparable precision to good land-based laboratories. We also examined contamination of certain elements caused by crushing during the use of the tungsten carbide apparatus. Although the concentrations of most elements are not altered during crushing, the powders prepared on the ship should not be used in subsequent studies where key elements of the investigation include W, $\mathrm{Co}, \mathrm{Ta}, \mathrm{Pb}$, and low levels of $\mathrm{Nb}$.
\end{abstract}

\section{INTRODUCTION}

Although a general description of the sample preparation, X-ray fluorescence (XRF) operating conditions, and data quality are outlined in the "Explanatory Notes" in the Initial Reports volume for Leg 135 (Parson, Hawkins, Allan, et al., 1992), a complete presentation of the replicate analyses of standards run over the duration of the cruise is not given. In addition, the comments made regarding trace element contamination of rock powders caused by crushing in the tungsten carbide swing-mill are necessarily brief and generalized. In this short contribution, we seek to explore these two issues in more detail.

\section{SHIPBOARD X-RAY FLUORESCENCE}

\section{Precision}

For specific details regarding the preparation of fused beads and pressed powder pellets, the reader is referred to the "Explanatory Notes" of the Initial Reports volume (Parson, Hawkins, Allan, et al., 1992). The instrument used for the XRF analysis of whole-rock major and trace element compositions is a fully automated wavelength-dispersive ARL8420 (3 kW) system equipped with a Rh-target X-ray tube. The operating conditions are given in table 4 of the "Explanatory Notes" chapter.

\section{Major Elements}

The results of 32 separate analyses of standard K1919 are given in Table 1. Included in this table are the mean $(\mu)$ and standard deviation $\left(\sigma_{n-1}\right)$ of individual measurements, as well as the coefficient of variation ( $\varepsilon \%)$, and an additional column illustrating $\varepsilon \% / \sqrt{ } 2$. This latter parameter is the variance estimated for replicate measurements and is pertinent to the major element analyses of the unknowns, as these were all performed in duplicate (to reduce the errors involved in weighing; see "Explanatory Notes").

The maximum value of $\varepsilon \% / \sqrt{ } 2$ is $2.7 \%\left(\mathrm{P}_{2} \mathrm{O}_{5}\right)$, whereas for $\mathrm{SiO}_{2}$, $\mathrm{Al}_{2} \mathrm{O}_{3}, \mathrm{Fe}_{2} \mathrm{O}_{3}, \mathrm{MgO}, \mathrm{CaO}$, and $\mathrm{K}_{2} \mathrm{O}$ it is less than $1 \%$. The average coefficient of variation for $\mathrm{Fe}_{2} \mathrm{O}_{3}$ is 0.23 , corresponding to a value of $0.16 \%$ for duplicated measurements. This compares favorably with land-based XRF laboratories producing high-quality data; for exam-

\footnotetext{
' Hawkins, J., Parson, L., Allan, J., et al., 1994. Proc. ODP, Sci. Results, 135: College Station, TX (Ocean Drilling Program)

2 Department of Earth Sciences, The Open University, Walton Hall, Milton Keynes, MK7 6AA, United Kingdom (present address: School of Earth Sciences, The University of Melbourne, Parkville, Victoria, 3052, Australia).

${ }^{3}$ Ocean Drilling Program, Texas A\&M Research Park, 1000 Discovery Drive, College Station, TX 77845-9547, U.S.A.
}

ple, average values of $0.37 \%(\varepsilon \%)$ and $0.26 \%(\varepsilon \% / \sqrt{2})$ are reported for $\mathrm{Fe}_{2} \mathrm{O}_{3}$ by Chappell and Hergt (1989) for a similar assessment of the XRF facilities at the Australian National University (ANU).

Hergt et al. (1989) present an independent estimate of the analytical precision of the ANU laboratory based on eight individual preparations of the standard $\mathrm{W}-2$. Their values obtained for $\varepsilon \% / \sqrt{2}$ are included in Table 1 and compare well with the results of the shipboard measurements. In many cases, the uncertainties estimated for the two instruments are quite similar; however, for $\mathrm{SiO}_{2}, \mathrm{TiO}_{2}, \mathrm{MnO}$, and $\mathrm{P}_{2} \mathrm{O}_{5}$, the values deviate significantly. For example, for $\mathrm{SiO}_{2}$, the uncertainty associated with the shipboard measurements is approximately twice as large as that estimated for the laboratory at the ANU. Reference to Figure 1 indicates that significant drift occurred toward the end of data collection during Leg 135 . The $\mathrm{SiO}_{2}$ values of $\mathrm{K} 1919$ clearly show a sharp increase, which results in the higher uncertainties associated with this element in Table 1. If these last six results are excluded from the analysis, $\varepsilon \% / \sqrt{ } 2$ is reduced to $0.35 \%$, which is close to the ANU value.

It is worth noting that the analyses of standards are performed frequently precisely to monitor this type of drift, and the data for the unknowns run during this late-stage of the cruise could be corrected by an appropriate factor. Even so, the drift is within $2 \sigma$ uncertainty of the mean, and this small increase in the errors is unlikely to alter any interpretations of the results.

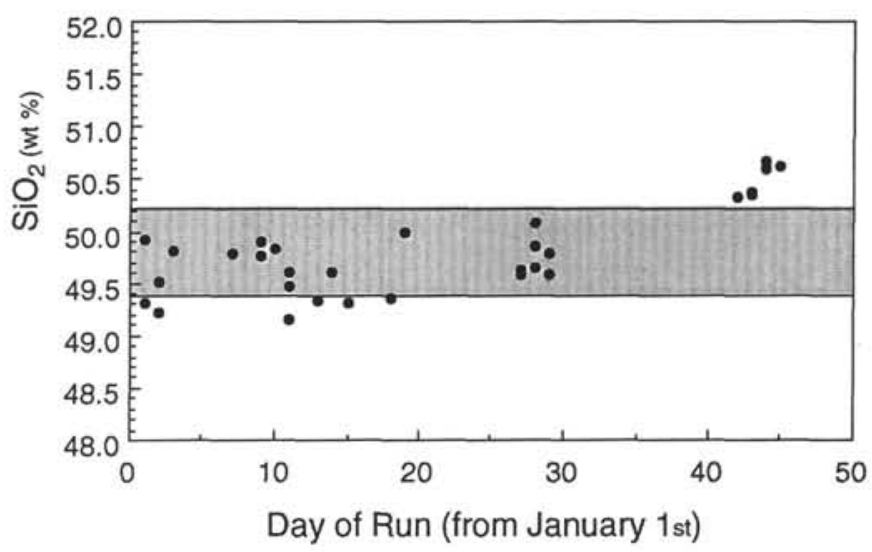

Figure 1. A plot of $\mathrm{SiO}_{2}$ measured in the standard K1919 during the same interval as the unknowns during Leg 135. The shaded rectangle represents the region spanning the $1 \sigma$ variation either side of the mean. Although the last six measurements fall outside this area and suggest some machine drift, they are within $2 \sigma$ analytical uncertainty of the mean. 
Table 1. Replicate analyses of K1919 obtained over the same period as the data acquired for unknowns during Leg 135.

\begin{tabular}{|c|c|c|c|c|c|c|c|c|c|c|c|c|}
\hline K1919 & Day & $\mathrm{SiO}_{2}$ & $\mathrm{TiO}_{2}$ & $\mathrm{Al}_{2} \mathrm{O}_{3}$ & $\mathrm{Fe}_{2} \mathrm{O}_{3}$ & $\mathrm{MnO}$ & $\mathrm{MgO}$ & $\mathrm{CaO}$ & $\mathrm{Na}_{2} \mathrm{O}$ & $\mathrm{K}_{2} \mathrm{O}$ & $\mathrm{P}_{2} \mathrm{O}_{5}$ & Total \\
\hline 834 & 1 & 49.30 & 2.75 & 13.66 & 11.98 & 0.16 & 6.96 & 11.30 & 2.36 & 0.55 & 0.28 & 99.30 \\
\hline 834 & 1 & 49.93 & 2.75 & 13.63 & 12.04 & 0.17 & 6.96 & 11.27 & 2.40 & 0.53 & 0.27 & 99.95 \\
\hline 834 & 2 & 49.51 & 2.77 & 13.45 & 12.01 & 0.16 & 6.96 & 11.32 & 2.40 & 0.53 & 0.27 & 99.38 \\
\hline 834 & 2 & 49.21 & 2.75 & 13.60 & 11.99 & 0.17 & 6.95 & 11.32 & 2.43 & 0.54 & 0.28 & 99.24 \\
\hline 834 & 3 & 49.81 & 2.75 & 13.60 & 11.95 & 0.16 & 6.72 & 11.27 & 2.41 & 0.54 & 0.27 & 99.48 \\
\hline 834 & 7 & 49.79 & 2.76 & 13.59 & 12.03 & 0.16 & 6.89 & 11.25 & 2.45 & 0.53 & 0.27 & 99.72 \\
\hline 834 & 9 & 49.90 & 2.73 & 13.65 & 12.04 & 0.16 & 6.90 & 11.27 & 2.44 & 0.54 & 0.27 & 99.90 \\
\hline 834 & 9 & 49.76 & 2.75 & 13.52 & 11.99 & 0.16 & 6.89 & 11.32 & 2.42 & 0.54 & 0.27 & 99.62 \\
\hline 834 & 10 & 49.82 & 2.77 & 13.66 & 11.98 & 0.16 & 6.84 & 11.25 & 2.37 & 0.54 & 0.27 & 99.66 \\
\hline 834 & 10 & 49.84 & 2.75 & 13.51 & 12.08 & 0.16 & 6.87 & 11.26 & 2.46 & 0.53 & 0.26 & 99.72 \\
\hline 834 & 11 & 49.60 & 2.99 & 13.68 & 12.01 & 0.17 & 7.04 & 11.22 & 2.45 & 0.53 & 0.30 & 99.99 \\
\hline 835 & 11 & 49.46 & 2.99 & 13.55 & 12.00 & 0.17 & 6.91 & 11.23 & 2.45 & 0.55 & 0.29 & 99.60 \\
\hline 835 & 11 & 49.16 & 2.97 & 13.60 & 12.00 & 0.16 & 7.03 & 11.32 & 2.43 & 0.54 & 0.31 & 99.52 \\
\hline 836 & 13 & 49.34 & 2.76 & 13.54 & 12.05 & 0.17 & 6.81 & 11.28 & 2.45 & 0.54 & 0.27 & 99.21 \\
\hline 836 & 14 & 49.61 & 2.75 & 13.65 & 12.02 & 0.17 & 6.96 & 11.31 & 2.42 & 0.55 & 0.28 & 99.72 \\
\hline 837 & 15 & 49.30 & 2.73 & 13.70 & 12.02 & 0.17 & 6.88 & 11.33 & 2.42 & 0.55 & 0.28 & 99.38 \\
\hline 838 & 18 & 49.35 & 2.76 & 13.61 & 11.98 & 0.17 & 6.71 & 11.37 & 2.38 & 0.54 & 0.28 & 99.15 \\
\hline 838 & 19 & 50.00 & 2.75 & 13.55 & 12.05 & 0.16 & 6.92 & 11.26 & 2.50 & 0.54 & 0.27 & 100.00 \\
\hline 839 & 27 & 49.59 & 2.76 & 13.61 & 11.98 & 0.16 & 6.91 & 11.33 & 2.46 & 0.53 & 0.28 & 99.61 \\
\hline 839 & 27 & 49.63 & 2.75 & 13.56 & 12.00 & 0.16 & 6.91 & 11.33 & 2.58 & 0.54 & 0.28 & 99.74 \\
\hline 839 & 28 & 49.85 & 2.75 & 13.50 & 12.03 & 0.17 & 7.04 & 11.33 & 2.46 & 0.55 & 0.28 & 99.96 \\
\hline 839 & 28 & 50.08 & 2.75 & 13.59 & 12.03 & 0.18 & 6.85 & 11.26 & 2.49 & 0.54 & 0.28 & 100.05 \\
\hline 839 & 28 & 49.66 & 2.74 & 13.62 & 12.03 & 0.17 & 6.86 & 11.29 & 2.47 & 0.54 & 0.28 & 99.66 \\
\hline 839 & 29 & 49.59 & 2.77 & 13.57 & 12.03 & 0.16 & 6.98 & 11.26 & 2.46 & 0.55 & 0.27 & 99.64 \\
\hline 839 & 29 & 49.78 & 2.75 & 13.59 & 12.03 & 0.16 & 6.90 & 11.25 & 2.47 & 0.54 & 0.28 & 99.75 \\
\hline 839 & 29 & 49.59 & 2.78 & 13.47 & 12.00 & 0.16 & 6.84 & 11.31 & 2.54 & 0.54 & 0.27 & 99.50 \\
\hline 840 & 42 & 50.33 & 2.76 & 13.49 & 12.02 & 0.17 & 6.96 & 11.30 & 2.43 & 0.54 & 0.28 & 100.28 \\
\hline 841 & 43 & 50.38 & 2.75 & 13.59 & 12.03 & 0.16 & 6.97 & 11.29 & 2.48 & 0.54 & 0.28 & 100.47 \\
\hline 841 & 43 & 50.35 & 2.76 & 13.67 & 12.04 & 0.17 & 6.92 & 11.30 & 2.41 & 0.54 & 0.30 & 100.46 \\
\hline 841 & 44 & 50.61 & 2.77 & 13.45 & 12.03 & 0.17 & 6.93 & 11.27 & 2.43 & 0.54 & 0.29 & 100.49 \\
\hline 841 & 44 & 50.66 & 2.75 & 13.50 & 12.06 & 0.17 & 6.93 & 11.29 & 2.52 & 0.54 & 0.29 & 100.71 \\
\hline $\begin{array}{l}841 \\
N=32\end{array}$ & 45 & 50.63 & 2.78 & 13.48 & 12.05 & 0.17 & 7.02 & 11.33 & 2.52 & 0.54 & 0.29 & 100.81 \\
\hline$\mu$ & & 49.79 & 2.78 & 13.58 & 12.02 & 0.17 & 6.91 & 11.29 & 2.45 & 0.54 & 0.28 & \\
\hline & & 0.41 & 0.07 & 0.07 & 0.03 & 0.01 & 0.08 & 0.03 & 0.05 & 0.01 & 0.01 & \\
\hline$\varepsilon \%$ & & 0.83 & 2.47 & 0.51 & 0.23 & 3.43 & 1.13 & 0.31 & 1.98 & 1.15 & 3.85 & \\
\hline$\varepsilon \% / \sqrt{ } 2$ & & 0.6 & 1.8 & 0.4 & 0.2 & 2.4 & 0.8 & 0.2 & 1.4 & 0.8 & 2.7 & \\
\hline$\varepsilon \% / \sqrt{2}$ (ANU) & & 0.3 & 0.8 & 0.3 & 0.5 & 1.1 & 0.6 & 0.3 & 1.3 & 0.9 & 1.9 & \\
\hline
\end{tabular}

Note: The "day" is given from the start of the first day of analysis (January 1). The mean $(\mu)$, standard deviation $(\sigma[n-1])$, coefficient of variation $(\varepsilon \%)$, and variance $(\varepsilon \% / \hat{\mathrm{A}} 2)$ are given for these data. A row of the $\varepsilon \% / \hat{\mathrm{A}} 2$ estimated for the XRF facility at the Australian National University (ANU) is included for comparison (Hergt et al., 1989). Oxide data are given in weight percent.

Table 2. Replicate analyses of BHVO-1.

\begin{tabular}{|c|c|c|c|c|c|c|c|c|c|c|c|c|c|}
\hline BHVO-1 & Day & $\mathrm{Nb}$ & $\mathrm{Zr}$ & $\mathrm{Y}$ & $\mathrm{Sr}$ & $\mathrm{Rb}$ & $\mathrm{Zn}$ & $\mathrm{Cu}$ & $\mathrm{Ni}$ & $\mathrm{Cr}$ & V & $\mathrm{Ce}$ & $\mathrm{Ba}$ \\
\hline 834 & -2 & 19 & 167 & 27 & 394 & 9 & 108 & 137 & 122 & 293 & 319 & 42 & 140 \\
\hline 834 & 2 & 19 & & 27 & 393 & 9 & 112 & 138 & 121 & 284 & 324 & 38 & 132 \\
\hline 834 & 3 & 19 & 192 & 26 & 393 & 9 & 108 & 136 & 120 & 300 & 322 & 36 & 151 \\
\hline 834 & 3 & 19 & 193 & 26 & 394 & 9 & 109 & 134 & 122 & 281 & 314 & 31 & 155 \\
\hline 834 & 4 & 20 & 194 & 27 & 393 & 9 & 108 & 135 & 122 & 295 & 323 & 40 & 158 \\
\hline 835 & 7 & 19 & 193 & 27 & 392 & 9 & 112 & 136 & 121 & 285 & 318 & 37 & 155 \\
\hline 836 & 12 & 19 & 193 & 27 & 391 & 9 & 109 & 136 & 113 & 279 & 383 & 43 & 151 \\
\hline 836 & 12 & 19 & 193 & 27 & 392 & 9 & 108 & 137 & 122 & 306 & 314 & 31 & 163 \\
\hline 837 & 14 & 19 & 194 & 27 & 395 & 9 & 108 & 136 & 123 & 288 & 312 & 38 & 154 \\
\hline 838 & 16 & 19 & 193 & 27 & 397 & 9 & 109 & 136 & 122 & 303 & 324 & 32 & 172 \\
\hline 839 & 20 & 19 & 194 & 27 & 391 & 8 & 106 & 136 & 121 & 291 & 315 & 33 & 159 \\
\hline & 39 & 19 & 194 & 26 & 395 & 10 & 111 & 138 & 123 & 281 & 304 & 33 & 155 \\
\hline & 39 & 19 & 193 & 26 & 387 & 9 & 109 & 133 & 122 & $\begin{array}{l}201 \\
278\end{array}$ & 295 & 34 & 164 \\
\hline & 39 & 19 & 193 & 26 & 388 & 9 & 108 & 132 & 122 & 288 & 301 & 30 & 160 \\
\hline 840 & 41 & 20 & 195 & 26 & 390 & 9 & 108 & 134 & 125 & 291 & 300 & 35 & 145 \\
\hline 841 & 41 & 19 & 196 & 26 & 391 & 9 & 108 & 133 & 122 & 299 & 295 & 33 & 158 \\
\hline $\begin{array}{l}841 \\
N=17\end{array}$ & 42 & 19 & 196 & 26 & 390 & 9 & 110 & 134 & 123 & 287 & 294 & 28 & 161 \\
\hline$\mu$ & & 19.12 & 192.06 & 26.53 & 392.12 & 9.00 & 108.88 & 135.35 & 121.53 & 289.94 & 315.12 & 34.94 & 154.88 \\
\hline$\sigma_{(n-D)}$ & & 0.33 & 6.78 & 0.51 & 2.57 & 0.35 & 1.58 & 1.77 & 2.45 & 8.47 & 20.49 & 4.25 & 9.41 \\
\hline$\varepsilon \%$ & & 1.74 & 3.53 & 1.94 & 0.66 & 3.93 & 1.45 & 1.30 & 2.02 & 2.92 & 6.50 & 12.16 & 6.07 \\
\hline
\end{tabular}

Note: See note to Table 1 for date and analytical conventions. All elemental results are in ppm.

Similar tests do not support increased drift as the cause of the larger errors associated with $\mathrm{TiO}_{2}, \mathrm{MnO}$, and $\mathrm{P}_{2} \mathrm{O}_{5}$ (although the data for "Day 11 " are unusually high for $\mathrm{TiO}_{2}$ ). In addition, these components are not particularly low in K1919 compared with W-2; therefore, detection problems should not be the cause of the discrepancy. At the present time, it is not clear why these differences should exist.

\section{Trace Elements}

The trace element statistics are based on the repeated analysis of standard BHVO-1 and are presented in Table 2. Although the coefficient of variation of $\sim 12 \%$ is rather high in the case of $\mathrm{Ce}$, uncertainties for the other elements appear to be quite acceptable. It should be 
noted, however, that the uncertainties estimated in Table 2 for the trace elements critically depend on the concentrations of these elements in the standard. For example, although uncertainties of $<2 \%$ for $\mathrm{Nb}$ are excellent at the level of $\sim 20$ parts per million (ppm), we cannot expect to reproduce this standard of reproducibility when measuring $\mathrm{Nb}$ in rocks close to (or below) the detection limit.

Clearly, it is of little use to measure standard materials with low levels of certain trace elements routinely so as to approximate uncertainties at lower abundances better; poor results could be related either to low peak-to-background ratios and counting statistics or to problems with the instrumentation. The purpose of repeatedly measuring BHVO-1, with its relatively high concentrations of various trace elements, is to monitor the behavior of the instrument and the calibration, rather than to provide exact estimates of the uncertainties expected for unknowns.

\section{Accuracy}

A brief comment on the accuracy is given in the "Explanatory Notes" (Parson, Hawkins, Allan, et al., 1992) using published values for K1919 and BHVO-1 for comparison (tables 3 and 5 in the reference cited). As BHVO-1 is used in the calibration of the trace element program, the data acquired during Leg 135 do not offer an independent test of the accuracy of the instrument. Instead, in the course of investigating contamination associated with crushing, the trace element concentrations of two samples measured on the ship were repeated by inductively coupled plasma mass spectrometry (ICPMS; see later discussion). The results of these entirely independent analyses are given in Table 3 and are extremely encouraging. The differences between the shipboard and land-based data generally are less than or similar to the anticipated analytical uncertainties of the XRF data, particularly in the case of Sample 135-834B-14R-1, $33-40 \mathrm{~cm}$. Exceptions to this might include $\mathrm{Ba}, \mathrm{Ce}$, and $\mathrm{Nb}$; however, as mentioned already, these elements will be prone to greater uncertainties when measured by XRF given their significantly lower abundances in these samples compared with BHVO-1. In fact, given that BHVO- 1 contains $20 \mathrm{ppm} \mathrm{Nb}$ and the two samples have between 1 and $2 \mathrm{ppm}$, the agreement is excellent. Clearly, a comparison between single analyses of only two samples is no basis to test statistically the accuracy of the trace element values obtained on the JOIDES Resolution. It does, however, provide one example of outstanding agreement between the shipboard data and a completely different technique using quite independent calibrations and correction procedures.

Although the shipboard results are clearly of a high quality, it may be possible to improve the accuracy of some elements by the incorporation of techniques outlined by Jochum et al. (1990). These authors presented a method by which more accurate results could be obtained by $\mathrm{XRF}$ for $\mathrm{Nb}$ and $\mathrm{Zr}$ present in low abundances in rock standards, and they compared their results with data obtained independently by spark source mass spectrometry. The recommended counting times for collection of data on both peak and background appear to be similar to that already employed on the JOIDES Resolution; however, Jochum et al. (1990) also suggest monitoring small drift effects by the frequent measurement of a glass disk doped with high levels of $\mathrm{Nb}$ and $\mathrm{Zr}$, and using these to correct the counts obtained on unknowns. These authors also calibrated spectral interferences and made subtle corrections to the baseline-subtracted counts (e.g., $0.0026 \mathrm{ppm} \mathrm{Nb/ppm} \mathrm{Y).} \mathrm{It} \mathrm{is}$ possible that application of techniques described in Jochum et al. (1990) could further improve the already high standard of analyses available from the JOIDES Resolution XRF facility.

\section{SHIPBOARD SAMPLE PREPARATION}

\section{Crushing in Tungsten Carbide}

Whole-rock samples analyzed aboard the JOIDES Resolution are carefully selected so that any variation in composition between and within sites is documented. Also, the rocks are typically chosen from
Table 3. Comparison between analyses of splits from the same powders by ICPMS and shipboard XRF.

\begin{tabular}{|c|c|c|c|c|}
\hline & \multicolumn{2}{|c|}{$\begin{array}{c}135-834 \mathrm{~B}-14 \mathrm{R}-1, \\
33-40 \mathrm{~cm}\end{array}$} & \multicolumn{2}{|c|}{$\begin{array}{c}135-839 \mathrm{~B}-36 \mathrm{R}-1 \\
26-31 \mathrm{~cm}\end{array}$} \\
\hline & ICPMS & $\begin{array}{l}\text { Shipboard } \\
\text { results }\end{array}$ & ICPMS & $\begin{array}{l}\text { Shipboard } \\
\text { results }\end{array}$ \\
\hline $\mathrm{Ti}$ & 1.55 & 1.75 & 0.68 & 0.8 \\
\hline V & 269 & 289 & 299 & 346 \\
\hline $\mathrm{Cr}$ & 88 & 87 & 24 & 25 \\
\hline Mn & 0.16 & 0.17 & 0.16 & 0.18 \\
\hline $\mathrm{Ni}$ & 34 & 36 & 23 & 20 \\
\hline $\mathrm{Cu}$ & 58 & 63 & 86 & 97 \\
\hline $\mathrm{Zn}$ & 71 & 73 & 68 & 75 \\
\hline $\mathrm{Rb}$ & 4.8 & 5 & 6.0 & 6 \\
\hline $\mathrm{Sr}$ & 180.4 & 180 & 182.2 & 185 \\
\hline Y & 38.6 & 39 & 19.9 & 21 \\
\hline $\mathrm{Zr}$ & 143.7 & 147 & 32.0 & 44 \\
\hline $\mathrm{Nb}$ & 1.99 & 2 & 1.09 & 2 \\
\hline $\mathrm{Ba}$ & 25 & 43 & 67 & 84 \\
\hline $\mathrm{Ce}$ & 14.35 & 16 & 5.25 & 15 \\
\hline
\end{tabular}

Notes: All data are given in ppm except for Ti and $\mathrm{Mn}$, which are given in weight percent oxide. ICPMS = inductively coupled plasma mass spectrometry.

the most petrographically fresh areas of the core. For these two reasons, the powders prepared during each cruise represent an attractive suite of samples for additional land-based analytical work. Limitations resulting from time constraints and the large volume of analyses performed at sea requires a rapid sample preparation technique (e.g., 83 samples were processed from pieces of core through to whole-rock major and trace element analyses over a period of 57 days during Leg 135). Therefore, although agate and alumino-ceramic crushing apparatus were available on the JOIDES Resolution, these methods are far more time consuming, and the tungsten carbide mill (being significantly quicker) was routinely used. Clearly, rocks crushed in tungsten carbide will become contaminated with W; furthermore, it is known that contributions from Co and $\mathrm{Ta}$ are also likely, and $\mathrm{Nb}$ is a possibility (Joron et al., 1980). The exact quantity of these elements introduced into the rock powders during crushing is rarely examined in detail, but it probably varies from one set of apparatus to another. In addition, it is not clear what the contribution might be from other elements (e.g., $\mathrm{Pb}$ ).

The levels of many trace elements are particularly low in most of the igneous rocks recovered during Leg 135 (e.g., Hergt and Nilsson, this volume). Clearly, before additional work is conducted using the samples prepared during Leg 135 , it is desirable to assess more carefully how the concentrations of some elements may have been affected by contamination. The results of our analyses should be equally applicable to the powders produced as far back as Leg 111, during which the use of this same tungsten carbide swing mill was employed.

\section{Method}

To identify which elements may be introduced during crushing, a quantity of Spex specpure $\mathrm{SiO}_{2}$ was crushed in the mill under the same conditions and for the same period of time (i.e., $1 \mathrm{~min}$ ) as the basaltic unknowns. We acknowledge that differences may be present between the absolute abundances of elements introduced into the basalts and our test silica as a result of the different abrasive properties of the two materials. Other studies have sought to eliminate this by comparing splits of the same samples prepared in agate and tungsten carbide (e.g., Frey et al., 1991). In a similar manner, we have compared the data from two samples powdered on the ship with additional samples taken from exactly adjacent pieces of the core. As with the shipboard preparation, these adjacent samples were ground free from saw marks and ultrasoned in pure water. The pieces were then cracked in a carefully cleaned agate mortar and pestle, with clean, interior pieces handpicked for analysis using a binocular microscope. Sample 135839B-36R-1, 32-37 cm, an aphyric rock, was also crushed for $10 \mathrm{~min}$ 
in an agate ball-mill, whereas Sample 135-834B-14R-1, 28-32 cm, is a glass sample and was not further processed.

All of the samples were dissolved in ultrapure reagents prepared in the isotope laboratory at the Open University. Exactly $100 \mathrm{mg}$ of each sample were digested in twice-distilled concentrated HF and $\mathrm{HNO}_{3}$ (prepared using sub-boiling Teflon stills) in screw-top Savillex capsules. These were placed on a hotplate set at approximately $150^{\circ} \mathrm{C}$ overnight and evaporated to dryness in covered teflon pots under heating lamps and a flow of clean air. The residues were dissolved in a further $2 \mathrm{~mL}$ of concentrated $\mathrm{HNO}_{3}$ and again evaporated to dryness. Care was taken to remove the samples from the heating lamps before they turned brown from the oxidation of such elements as Fe and Mn. Although these metal oxides (and others with similar geochemical affinities) could have been redissolved using $\mathrm{HCl}$, we avoided the use of this acid as this would have resulted in spectral interferences during the analysis of the final solutions. After an additional $2.5 \mathrm{~mL}$ of $\mathrm{HNO}_{3}$ were added, the capsules were capped, wrapped in Parafilm, and carefully transported to the chemical laboratory at Durham University. Here, the solutions were spiked with a mixture of $\mathrm{Bi}, \mathrm{Rh}$, and $\mathrm{Re}$ (used as internal spikes for the drift corrections), and made up to 50 $\mathrm{mL}$ with Millipore water in polypropylene volumetric flasks.

The solutions were run on the VG inductively coupled plasma mass spectrometer (ICPMS), and the results are presented in Table 4. An average total procedural blank has been included to illustrate the increase in concentration of certain elements resulting from the reagents used. The other analyses have already been blank-corrected using these values.

\section{Results}

Given the nature of the tests, the results are not altogether simple to interpret. To begin with, the comparison between crushed and uncrushed silica must be viewed differently from the two processed rock samples. For example, although the crushed silica has approximately $50 \%$ more $\mathrm{Cr}$ compared with the uncrushed material, the reagent blank itself is of similar magnitude. This means that the blank correction was very large, and so the difference between the two silica samples is unlikely to be significant. Also, the calibration for $\mathrm{Cr}$ at these low levels is far less precise compared with the statistics for $\mathrm{Cr}$ contents of ppm. With problems such as this in mind, it would appear that there are really only clear indications of contributions to Co and
$\mathrm{Nb}$. Small deviations in $\mathrm{Ni}$ and $\mathrm{Cu}( \pm \mathrm{Ba} \pm \mathrm{La})$ may or may not be real; they are certainly not large relative to the concentrations measured in the basaltic rocks from Leg 135 (e.g., Table 3, and Hergt and Nilsson, this volume).

In the comparison between the shipboard and land-based analyses of the whole rocks, different complications should be considered. To begin with, the sample pairs are from adjacent parts of the core, rather than precisely the same piece of rock. Small changes in microphenocryst contents for example would produce real (but geological) variations in some elements. In addition, both rocks processed on the ship were crystalline, whereas Sample 135-834B-14R-1, 28-32 cm, is a glass and Sample 135-839B-36R-1, 32-37 cm, is an aphyric rock. This means that, although the glass sample was only chipped before being weighed, the aphyric rock needed to be crushed (in agate) to make the material homogeneous and the sample representative.

The results are broadly consistent with the silica test in that $\mathrm{Co}$ (as would be W and Ta) is clearly introduced during crushing; however, the contamination is far lower in the case of the basaltic rocks $(\sim 24$ ppm for rock crushing compared with $>150 \mathrm{ppm}$ in silica). Curiously, $\mathrm{Nb}$ contamination appears to be an irregular occurrence. Although the rock sample from Site 839 and silica show an increase of between approximately 1 and $2 \mathrm{ppm}$, the sample from Site 834 shows little or no $\mathrm{Nb}$ contamination. The sample from Site 834 is also unusual in that the $\mathrm{Cr}$ content is elevated in the sample crushed in tungsten carbide, as are $\mathrm{Rb}, \mathrm{Sr}$, and $\mathrm{Cs}$. It is possible that the latter may be explained by a small amount of alteration increasing the levels of these elements in the crystalline rock, compared with the glass; however, this does not explain the lack of $\mathrm{Nb}$ contamination in this sample.

Clearly, the $\mathrm{Co}$ and $\mathrm{Nb}$ contamination is (or can be) significant, and powders prepared using the tungsten carbide mill during Legs 111 and onward should not be used for the determination of these elements. In contrast, all other elements presented here appear to be free from a significant crushing blank, and the shipboard powders should be adequate for future studies involving these elements. We note here in agreement with Joron et al. (1990) and in contrast with Frey et al. (1991) that we found no evidence for the introduction of $\mathrm{Zn}$ caused by crushing in the tungsten mill.

In addition to those elements listed in Table 4, demonstration of the $\mathrm{Pb}$ contamination is particularly important for those considering using these powders for either $\mathrm{Pb}$-isotope work or investigations requiring accurate $\mathrm{Pb}$ contents. For example, $\mathrm{Pb}$ broadly shares the

Table 4. Comparison between silica and Leg 135 rock samples prepared by crushing in the shipboard tungsten carbide mill and split (or adjacent) samples prepared without the use of a mill composed of tungsten carbide.

\begin{tabular}{|c|c|c|c|c|c|c|c|}
\hline & $\begin{array}{c}\text { Chemistry } \\
\text { blank }\end{array}$ & $\begin{array}{l}\text { Crushed } \\
\text { silica } \\
\text { powder }\end{array}$ & $\begin{array}{l}\text { Unprocessed } \\
\text { silica } \\
\text { powder }\end{array}$ & $\begin{array}{l}135-834 \mathrm{~B}- \\
14 \mathrm{R}-1, \\
33-40 \mathrm{~cm}^{*}\end{array}$ & $\begin{array}{c}135-834 \mathrm{~B}- \\
14 \mathrm{R}-1, \\
28-32 \mathrm{~cm}\end{array}$ & $\begin{array}{l}135-839 \mathrm{~B}- \\
36 \mathrm{R}-1 \\
26-31 \mathrm{~cm} *\end{array}$ & $\begin{array}{c}135-839 \mathrm{~B}- \\
36 \mathrm{R}-1, \\
32-37 \mathrm{~cm}\end{array}$ \\
\hline $\mathrm{Sc}$ & 0.10 & 0.12 & 0.16 & 36.90 & 34.20 & 37.20 & 44.00 \\
\hline $\mathrm{Ti}$ & 0.00 & 0.00 & 0.00 & 1.55 & 1.72 & 0.68 & 0.79 \\
\hline V & 0.23 & 0.27 & 0.25 & 269.00 & 274.00 & 299.00 & 354.00 \\
\hline $\mathrm{Cr}$ & 1.13 & 1.55 & 1.05 & 88.00 & 68.00 & 24.00 & 27.00 \\
\hline $\mathrm{Mn}$ & 0.00 & 0.00 & 0.00 & 0.16 & 0.16 & 0.16 & 0.19 \\
\hline Co & 0.06 & 152.60 & 0.08 & 55.30 & 31.60 & 57.90 & 34.30 \\
\hline $\mathrm{Ni}$ & 0.82 & 3.43 & 0.88 & 34.00 & 35.00 & 23.00 & 28.00 \\
\hline $\mathrm{Cu}$ & 0.66 & 2.76 & 1.46 & 58.00 & 57.00 & 86.00 & 92.00 \\
\hline $\mathrm{Zn}$ & 4.59 & 3.33 & 4.69 & 71.00 & 83.00 & 68.00 & 83.00 \\
\hline $\mathrm{Ga}$ & 0.02 & 0.02 & 0.02 & 17.00 & 18.00 & 15.00 & 17.00 \\
\hline $\mathrm{Rb}$ & 0.03 & 0.05 & 0.07 & 4.80 & 1.30 & 6.00 & 7.50 \\
\hline $\mathrm{Sr}$ & 0.25 & 0.80 & 0.37 & 180.40 & 162.10 & 182.20 & 211.90 \\
\hline $\mathrm{Y}$ & 0.01 & 0.59 & 0.36 & 38.60 & 41.00 & 19.90 & 22.50 \\
\hline $\mathrm{Zr}$ & 0.14 & 0.96 & 0.61 & 143.70 & 140.60 & 32.00 & 38.40 \\
\hline $\mathrm{Nb}$ & 0.01 & 2.13 & 0.02 & 1.99 & 1.76 & 1.09 & 0.29 \\
\hline Cs & 0.00 & 0.01 & 0.01 & 0.16 & 0.05 & 0.11 & 0.15 \\
\hline $\mathrm{Ba}$ & 0.49 & 1.16 & 0.41 & 25.00 & 25.50 & 67.00 & 88.10 \\
\hline $\mathrm{La}$ & 0.01 & 0.07 & 0.02 & 4.66 & 4.60 & 2.08 & 2.38 \\
\hline $\mathrm{Ce}$ & 0.02 & 0.07 & 0.05 & 14.35 & 15.49 & 5.25 & 6.71 \\
\hline Pr & 0.01 & 0.02 & 0.01 & 2.46 & 2.28 & 0.88 & 1.06 \\
\hline $\mathrm{Nd}$ & 0.02 & 0.06 & 0.03 & 13.65 & 12.47 & 5.45 & 6.97 \\
\hline
\end{tabular}

Note: Tungsten carbide mill samples denoted with an asterisk $(*)$. 
same geochemical behavior as Ce so that during partial melting and subsequent fractional crystallization processes, the $\mathrm{Ce} / \mathrm{Pb}$ ratios may be little changed. It has been shown that in ocean ridge and ocean island basalts, the $\mathrm{Ce} / \mathrm{Pb}$ ratios are relatively uniform and average approximately $25 \pm 5$ (Hofmann et al., 1986; Newsom et al., 1986). This contrasts with the ratios observed in rocks from the continental crust and island arc magmas, which are typically very low (e.g., $~ 4$; Taylor and McLennan, 1985; Sun, 1980). The Ce/Pb ratios of magmas generated in the backarc environment are clearly of interest given their association with extension (as in the ocean ridge environment) and yet their proximity to island arc magmatism.

Because of the importance of this element in petrogenetic modeling, the magnitude of the $\mathrm{Pb}$ contamination in the silica samples was assessed using isotope dilution techniques at the Open University. The mean $\mathrm{Pb}$ content of the silica crushed in tungsten carbide is $0.45 \pm$ $0.04 \mathrm{ppm}$, compared with the concentration of $0.02 \pm 0.01 \mathrm{ppm} \mathrm{Pb}$ in the uncrushed material (errors are given as 1 standard deviation). This indicates a $\mathrm{Pb}$ contamination of approximately $0.43 \mathrm{ppm}$. Unfortunately, it has not been possible to repeat the experiment with the rock samples, and it is necessary to assume that a similar order of contamination would apply to the basaltic rock powders.

Given that the $\mathrm{Pb}$ content of the basalts recovered during Leg 135 is typically less than $1 \mathrm{ppm}$, and can be as low as $0.4 \mathrm{ppm}$ (Hergt and Nilsson, this volume), $\mathrm{Pb}$ contamination of this order is considerable and makes use of the powders prepared on the JOIDES Resolution unacceptable for detailed $\mathrm{Pb}$ work.

\section{SUMMARY}

The precision of major and trace element XRF analyses of unknowns run during Leg 135 was monitored using the standard rocks K1919 and BHVO-1, respectively. Statistical analyses of these data indicate that the results are as precise as can be produced in good land-based laboratories.

The contamination introduced into rock powders during sample preparation (using the shipboard tungsten carbide swing mill) has been tested and quantified. The results indicate that in addition to the $\mathrm{W}, \mathrm{Co}$, and $\mathrm{Ta}$ contamination expected, $\mathrm{Nb}$ and $\mathrm{Pb}$ contributions may also be significant.

We would conclude by suggesting that the major and (most of the) trace element data produced on board JOIDES Resolution are of excellent quality and are more than adequate for use either with or without other data sets produced in land-based studies. Although the shipboard data are adequate for most geochemical applications, a note of caution is recommended to those who conduct additional analytic work using the rock powders prepared on the ship, as these are likely to be contaminated in certain elements as a result of the crushing apparatus employed.

\section{ACKNOWLEDGMENTS}

We would like to thank Jamie Allan for encouraging this contribution, and Mike Storey for his constructive review. Thanks also to Dave Peate and Ian Parkinson for their great efforts in trying to generate the last of the ICPMS results by required deadlines. JMH gratefully acknowledges support from an NERC Special Topic grant.

\section{REFERENCES*}

Chappell, B.W., and Hergt, J.M., 1989. The use of Fe content as a flux monitor in neutron activation analysis. Chem. Geol., 78:151-158.

Frey, F.A., Jones, W.B., Davies, H., and Weis, D., 1991. Geochemical and petrologic data for basalts from Sites 756, 757, and 758: implications for the origin and evolution of Ninetyeast Ridge. In Weissel, J., Peirce, J., Taylor, E., Alt, J., et al., Proc. ODP, Sci. Results, 121: College Station, TX (Ocean Drilling Program), 611-659.

Hergt, J.M., Chappell, B.W., McCulloch, M.T., McDougall, I., and Chivas, A.R., 1989. Geochemical and isotopic constraints on the origin of the Jurassic dolerites of Tasmania. J. Petrol., 30:841-883.

Hofmann, A.W., Jochum, K.P., Seufert, M., and White, W.M., 1986. Nb and $\mathrm{Pb}$ in oceanic basalts: new constraints on mantle evolution. Earth Planet. Sci. Lett., 79:33-45.

Jochum, K.P., Seufert, H.M., and Thirlwall, M.F., 1990. High-sensitivity Nb analysis by spark-source mass spectrometry (SSMS) and calibration of XRF $\mathrm{Nb}$ and $\mathrm{Zr}$. Chem. Geol., 81:1-16.

Joron, J.L., Briqueu, L., Bougault, H., and Treuil, M., 1980. East Pacific Rise, Galapagos spreading center and Siqueiro Fracture Zone. Hygromagmaphile elements: a comparison with the North Atlantic. In Rosendahl, B.R., Hekinian, R., et al., Init. Repts. DSDP, 54: Washington (U.S. Govt. Printing Office), 725-735.

Newsom, H.E., White, W.M., Jochum, K.P., and Hofmann, A.W., 1986. Siderophile and chalcophile element abundances in oceanic basalts: $\mathrm{Pb}$ isotope evolution and growth of the Earth's core. Earth Planet. Sci. Lett., 80:299-313.

Parson, L., Hawkins, J., Allan, J., et al., 1992. Proc. ODP, Init. Repts., 135: College Station, TX (Ocean Drilling Program).

Sun, S.-S., 1980. Lead isotopic study of young volcanic rocks from mid-ocean ridges, ocean islands and island arcs. Philos. Trans. R. Soc. London A, 297:409-445.

Taylor, S.R., and McLennan, S.M., 1985. The Continental Crust: Its Composition and Evolution: Oxford (Blackwell Scientific).

\footnotetext{
- Abbreviations for names of organizations and publication titles in ODP reference lists follow the style given in Chemical Abstracts Service Source Index (published by American Chemical Society).
}

Date of initial receipt: 29 June 1992

Date of acceptance: 5 May 1993

Ms 135SR-143 